BAXTER, L.R., ROY-BYRNE, P., LISTON, E.H. et al (1986) Informing patients about electroconvulsive therapy: effects of a videotape presentation. Convulsive Therapy, 2, 2529.

Freeman, C.P.L. \& Cheshire, K.E. (1986) Attitude studies on electroconvulsive therapy. Convulsive Therapy, 2, 31-42. HORGAN, D. (1990) Prejudice against ECT (letter). Australian \& New Zealand Journal of Psychiatry. 24, 157-158.

S. M. BENBOW, York House, Manchester Royal Infirmary, Manchester M13 9BX

Sir: We thank Dr Benbow for her comments. We agree that the Freeman $\&$ Cheshire study did not reveal strong antipathy towards ECT, but other studies (Selvin, 1987; Durham, 1989) discuss the controversies regarding its use. We have personal experience of strong negative opinions expressed by both professional colleagues and others. Combined with views expressed in the media, which must represent the views of a proportion of the population, we feel that we were justified in using the phrase "widely seen". We are aware of the anecdotal nature of some of this evidence.

Our suggestions regarding the use of other formats to aid explanation of the ECT process were not based on personal experience. We would suggest that further work, looking at the efficacy of these methods, would be invaluable.

DURHAM. J. (1989) Sources of public prejudice against electroconvulsive therapy. Australian and New Zealand Journal of Psychiatry, 23, 453-460.

SElvin. B.L. (1987) Electroconvulsive therapy. Anaesthestology. 67, 367-385

DENISE M. RIORDAN, Prestwich Hospital, Manchester M25; PHILIP BARRON, Northgate Hospital, Morpeth, Northumberland NE61 3BP; and MELANIE F. BOWDEN, formerly Manchester Royal Infirmary, Manchester M13

\section{Training in administration of ECT}

Sir: A similar survey to $\mathrm{Dr}$ Henderson's on ECT (Psychiatric Bulletin, 1993, 17, 154-155) was carried out among psychiatrists of East Berkshire, using an anonymous, self-completed questionnaire. Numbers involved were small but may be of some interest as they compared experiences of present trainees with more senior colleagues.

Questionnaires were sent to all psychiatrists in East Berkshire: seven 'trainees' $(t)$ and 13 'others' (o) (consultants, associate specialists, clinical assistants). All trainees and eight others replied. Average time in training was 103 weeks for trainees and 19 years for others. Thus most others received their training before Pillard \& Ellam's original survey of 1981 . Questions were asked about points considered to be good practice in training to administer ECT. Respondents who were no longer trainees were asked to reply with respect to their original training.

Initial questions concerned consultant cover of the ECT department. Three (t) and four (o) knew that there was a consultant responsible for training juniors. No trainees and two others recalled seeing the nominated consultant in the department regularly. Three ( $t$ ) but all others knew of an allocated person with whom they could discuss problems concerning ECT.

Two (t) and three (o) had received an initial seminar prior to administering ECT. Three $(t)$ and three (o) had the nominated consultant or his deputy present during the initial ECT session, while five (t) and five (o) had ECT demonstrated by a more senior trainee. The number of sessions observed before administering ECT alone varied. Four ( $t$ ) and three (o) had observed one session. while one of each group had observed more than one.

The study was carried out as part of an audit of ECT in our department. Concern was voiced that trainees' perception of training did not match that of the senior staff who felt that there was a consultant in charge of ECT who made a point of training juniors. The other findings were not challenged. These findings suggest that over the last 10-15 years there has been no great change in the level of training received. In most areas the 'others' did as well as or better than the 'trainees'.

PIPPARD, J. \& ELLAM, L. (1981) Electroconvulstue Treatment in Great Brtain. 1980. London: Gaskell (Royal College of Psychiatrists).

Elizabeth A. QuinN, Chilton Clinic, Warneford Hospital, Oxford OXC3 7JX

\section{Care programme approach in Shropshire district}

Sir: We would like to report our findings from a study undertaken 16 months following the inception of care programme approach (CPA) in Shropshire district. Professionals involved in the initiation and present workings of the CPA were interviewed.

The Planning and Information Department's role to monitor information, and thereby look for needs and changes for future service requirements, were not wholly met. Computer listing of allocated patients was not sent to the relevant keyworkers. This lead to lack of vital communication. The sheer volume of forms $(20,000$ a year) was too great to process with available resources and was regarded as yet another exercise in bureaucracy and red tape unlikely to effect change in clinical practice.

The community psychiatric nursing services (CPNS) were aware of their obligation to the CPA and felt it was a realistic objective despite 